Maritta Törrönen*, Carol Munn-Giddings, Chrissie Gavriel and Demi Morris

Prof. Maritta Törrönen, Anglia Ruskin University, School of Education and Social Care, Faculty of Health, Social Care and Education, William Harvey Building $4^{\text {th }}$ Floor, Chelmsford Campus, Bishop Hall Lane, Chelmsford, Essex CM1 1SQ, UK, tel: 0845-196-3607, Email:

Maritta.Torronen@anglia.ac.uk,

ORCID identifier J-5353-2014, Twitter: @LMTorronen, Linkedln:

maritta.I.torronen@helsinki.fi, homepage: http://blogs.helsinki.fi/mtorrone/

Prof. Carol Munn-Giddings, School of Education and Social Care

Faculty of Health, Social Care and Education

Anglia Ruskin University, UK, Email: Carol.Munn-Giddings@anglia.ac.uk

This work was supported by the EU under Marie Sklodowska-Curie Scholarship.

\title{
Emotional Participation of Young Adults Starting their Independent Living
}

\section{Abstract}

How to ensure young adults are active partners in society is an issue across Europe. This issue has a particular relevance for young people leaving the care system who may have been disadvantaged by their care experiences. Drawing on selected findings from the EUfunded study 'Reciprocal Encounters - Young adults leaving care' funded by European Union (2016-2018) we ask what supports and hinders meaningful participation in their communities?

The study design was participatory action research involving young people with leaving care experiences in question-setting, research design, ethical review, data generation, analysis or dissemination from both Finland and the UK. The data consists of 50 Finnish and 24 English peer interviews which were thematically analysed.

The central message from the young people was the importance they attributed to the meaning and continuity of social connections which support what we define as their 'emotional participation'. To understand this concept and practice we draw on a theoretical discussion of reciprocity.

A core similarity in both countries is that young people long for stability in their relationships. Findings are presented along a spectrum describing experiences where young adults feel themselves emotionally connected to other persons and when there is more emotional distance. Different welfare practices shape these experiences, for example: the English services stressing child protection and the Finnish services stressing individualisedliberty practice. Both can strengthen or weaken emotional participation. We conclude by suggesting a move from individualistic practice towards community practice which has at its core the importance of supporting reciprocal relationships.

\section{Keywords:}


Reciprocity, social capital, interdependence, emotional participation, belonging, well-being, leaving care, participatory action research

\section{Introduction}

In times of uncertainty in the postmodern world it is important we can have a feeling that we as human beings have something in common. We are social creatures who need other people to help and support us, the feeling that we belong somewhere and are important to someone. They create the fundamental condition of survival and self-realisation (Törrönen $2017, x)$. They also create the conditions for meaningful participation in a society.

In our research, young adults who have been in care have told us a very important message about what enables or constrains their participation from their perspective. Their wish is to be socially and emotionally attached to other people. Social relationships contain emotions which reveal the quality of the relationship. As we age we learn to trust other people or otherwise depending on our experiences of how we are trusted and cared for.

Young adults in our study foregrounded stability in relationships as the most important element for them in terms of what they would like to have supported from child and youth services. For instance, if placements are changing regularly it means instability. As one peer researcher told us, when your placement is changing it is like 'you have to start from the beginning'. You move to a different and unknown area and environment, you have new social contacts in the placement and the school and maybe have difficulties in keeping your other important social contacts. It is like you are alone doing that journey. Maybe you feel rejected, abandoned and unsuccessful. It might be like a repetition of the rejection when you are moved away from your childhood home.

However, after some time you might be satisfied with the change and learn to know people, find your place in the school and develop hobbies, and feel well. Unfortunately, this is not the case with all young adults. Usually, the larger the number of placements, the more difficult it is to find connection and trust the people you meet. It can give you feelings such as 'I do not belong anywhere' or 'I really did not have my own home'.

In this article, the main message learned from young adults is the meaning and continuity of social connections which support what we term as their emotional participation (see 
Korkiamäki and Ellonen 2010, 19-20; Morrow 1999). We explore emotional participation in relation to the theory of reciprocity. We propose that social work practice underpinned by and fostering reciprocal relationships (reciprocal social work - see Törrönen et al. 2017) can be seen as a contribution to international social welfare research, where attention is focused on well-being and the communities that hold people together (see Becker 1986; Ostrom and Walker 2003). Reciprocity refers both to social relations but also to power relations. Hence, the concept is not only about the interaction between people; it includes emotional and evaluative functions. (Törrönen 2015).

\section{Reciprocal Interdependence}

In terms of a definition, reciprocity is linked to the concept of social support, which describes interaction as a form of intervention and activity. When we are in a reciprocal relationship we both give to and gain from that relationship. We are inter-dependent. Reciprocity is closely associated with such concepts as "sociability, social networks, trust, community and civic engagement" (Morrow 1999), social capital (Coleman 1990) and ideas of helping and solidarity (e.g., Lindenberg et al. 2010).

Reciprocity appears when young adults have a feeling of shared action and believe they can trust someone, which creates social bonding and a feeling of being included and belonging. This is based on the idea that how individuals are committed to and how much they participate in their own community is in relation to the role of social support in their life and how they experience this support (Newcomb 1990). Stability demands some kind of continuity in the social networks that support individuals, although the nature and quality of those social networks also impacts what kind of resources they offer and how young adults can benefit from them (Korkiamäki and Ellonen 2010, 19).

Reciprocal social work sees that the well-being of human beings contains holistically material, physical, mental, social, emotional and existential elements (Törrönen 2017, x). As with social policy, in social work you cannot forget living conditions which include the material opportunities to satisfy your needs, which usually impact physical and mental 
health (see Nyman et al. 2017). Too often the parents whose children are in care suffer from poverty and bad health (Saarikallio-Torp et al. 2010).

A model of practice that we call 'reciprocal social work' (Törrönen et al. 2017) incorporates understanding of reciprocity and holistic notions of well-being at its heart. This approach would add a new dimension to the movement towards relational social work (see for instance Ward 2010) which highlights the importance of social relationships and points out the meaning of dialogue and respect in encounters. It would also complement strengthsbased approaches (Saleebey 1997) and the (slow) move since the 1970s to foreground the client's experiences and views (Mayer and Timms 1970) and develop related research approaches which are based on participatory methods that involve clients of social services in shaping their future (see for instance Franklin and Sloper 2006, 724-725; Winter and Munn-Giddings 2001).

\section{Emotional Participation}

As Franklin and Sloper $(2006,726)$ state, the term 'participation' covers a broad continuum of involvement and is a multi-layered concept (see also Participation Models 2012). They see that it can simply mean taking part, being present, being involved or consulted. In their view participation can be seen as a process where the level of participation varies according to the degree of power that is shared or transferred.

Although we see the holistic nature of well-being, we focus in this article on findings that have illuminated the reciprocal interdependence (or otherwise) and enabled (or otherwise) what we term emotional participation by young adults. We concentrate our analysis in relation to young adults' experiences of social and emotional support (see also Paulsen \& Berg 2016, 128) and advice when they started their independent living, a critical period of young adults' everyday life. It reveals the interplay between services offered by local authorities, private services and informal actors, and how these work together in vulnerable life situations. In this article we ask, how does emotional participation look from the perspective of young adults who are leaving care? Are they being involved in decisions about their life or are they only consulted and advised by other people? 
The term 'emotional participation' therefore can be understood as an individual's attachment to a community and its people and how much they feel they belong and can therefore participate in that community. It is a feeling of involvement, of being connected to different social networks and other people through mutual obligations (Törrönen 2017, x). In contrast, not to participate emotionally can engender the opposite feelings such as loneliness or solitude and can be painful. As human beings, we need other people's recognition in order to create a sense of belonging both as individuals but also citizens. As individuals in our social networks we have mutual obligations but also, we get and give support and care. It can also be a sense of solidarity with a wider community based on, for instance, neighbourhood, nation, wealth, disability, sexual orientation, and gender. From the societal aspect, emotional participation means how the person feels to be part of the wider community. It is expected that a well-connected individual in a well-connected society is likely to be better connected to the society than, for instance, a well-connected individual in a loosely connected society (Putnam 2000).

\section{Participatory action research, Data and the Analysis}

In our study participation has different meanings: we use it as a methodological tool but also as the study subject. The aim was not to do research on young adults but with them.

Similarly to Holland et al. $(2008,3)$ we understand that participative research with young people involves participants in some of the process of research, such as question-setting, research design, ethical review, data generation, analysis or dissemination rather than simply providing data through more or less engaging methods (see also Holland, et al. 2008, Involve 2016, 1; O'Brien 2016, 51). These were also the phases we had in our process with young adults who we engaged and trained as peer researchers.

We understand that methodologically participation is part of a complex inter-subjective relationship between adults and children where both adults and children are being encouraged to step outside normative generational roles (Holland et al. 2008, 3). It engages young adults in research (Campbell \& Trotter 2007, 33). It can also allow young adults to 
take ownership of the research, its design, results and implementation of its recommendations (Daly 2009, 462). A collaborative, co-sharing approach enables interpretations to remain rooted in the experience of participants (Cotterell 2008, 9).

Doing research with young adults who have been in care and have experiences of living in foster families or residential care is a moving journey. It makes it possible to learn to know each other and discuss the research subject in many ways. Young adults are not just numbers or names on the case records. They are young people with their desires and experiences. As researchers, practitioners or young adults as peer researchers cannot only rationally follow how the interviewed young adults struggle with their everyday life, you as persons with different personalities are also involved with your feelings.

We locate our approach as Participatory Action research as the overall aim has been to develop an understanding of how to act in practice and also to work together to create preventive or proactive welfare policies and social work guidelines. Winter and MunnGiddings $(2001,5)$ describe action research as simultaneously a form of inquiry and a form of practical action which involves people in a process of change in professional, organisational or community action. This study tries to provide shared investigations with people who traditionally may be marginalised and also gave them tools to make changes in their lives (see O’Brien 2016, 50).

Participatory action research offers non-institutional experiences and knowledge from young adults' lives (Campbell \& Trotter 2007). However, research with children or young adults has many tensions to address and concerns about possible exploitation and many practicalities such as child protection, informed consent and gatekeeper issues (Kellett 2003). These need to be thought through well and that is why appropriate training is needed. Ethical approval (reference number ESC-DREP-15-225) in the UK was given from Anglia Ruskin University and the Regional Council. The ethical considerations were agreed in the Finnish case with interviewed young adults who were over 18 years old before each interview. The interviewees were asked to give informed consent in both cases. 
The project is perhaps unusual in that different groups of young people from different countries were involved at different stages of the research process. The project evolved from a multi-country EU project "The children's rights in alternative care, from theory to practice: Filling the vacuum through peer research", a 2011-2012 EU and SOS Children's Villages International project (see Stein and Verweijen-Slamnescu 2012; Törrönen and Vauhkonen 2012a, 2012b) which involved young people working with academics to develop a questionnaire exploring leaving care experiences (from which the Finnish case in this article is derived). The current EU study drew on this data but involved the recruitment and training of peer researchers in a region in the South East of England.

We were working with peer researchers as a group. The research team consisted of young adults as peer researchers (the Finnish case $\mathrm{N}=10$; the English case $\mathrm{N}=11$ ) with leaving care experiences, practitioners (both countries $\mathrm{N}=3$ ), and university researchers (the Finnish case $\mathrm{N}=2$; the English case $\mathrm{N}=4$ ). The practitioners in the social services and NGOs served as gatekeepers who chose the young adults as peer researchers. They were aged from 18 to 32 years, had all been in care for varying numbers of years and had experience of different forms of care. They were trained to learn basic research skills and to undertake peer interviews and co-analysis. We had practitioners who knew the peer researchers and could support them not only throughout the process but also after it. Whilst working in the groups we noticed as Holland et al. did $(2008,24)$ that this was potentially more empowering for young people who were able to have fun together, share common experiences and, and as a group, hold sway over the researchers' presence.

The study contains approximately two years' fieldwork and peer interviews from the UK and Finland - representing different welfare states in Europe and their child welfare services. The interviewees we reached with the snowball-method. The data set for the Finnish case with 5.5 million inhabitants contains 50 interviews (years 2011-2012,) and the English data represents a county in Eastern England with 1.4 million inhabitants with 24 interviews (years 2016-2017). 
The interview schedule which had 18 background questions and 53 open and closed questions was developed with young adults in the first project and then modified with peer researchers for the English case. The peer researchers interviewed their peers both in Finland and in the UK. The recorded interviews were transcribed containing 34 hours (Finnish case) and 15 hours (English case).

Because there are no records on the young adults who have left care, there were difficulties in reaching potential participants. The interviewees were people who visited youth centres or who were otherwise still in contact with child and youth services or organisations. This may have created limitations to our data. In addition because the questions were modified in the different phases of the research which may have limited the potential to probe deeper into some subject areas. Some interviewees had difficulties in understanding some questions but the interviewers tried to explain them as well as they could. Some answered very briefly and some explained their experiences in more detail.

The core characteristics of interviewees are detailed in Table 1 below.

\section{Insert table here}

Of note from the table is that:

- More young women than men agreed to be interviewed in Finland - the reverse being the case in England.

- Both samples had a wide experience of different forms of care

- In terms of those not working or studying the proportion was much higher in England (42\%) compared to $20 \%$ in Finland

- Residential care was the last form of placement for most of the sample in Finland compared to foster care or semi-independent living for their English counterparts

- In both cases a quarter of interviewees had only one placement.

- Placements were considerably higher for the English sample with over 36 per cent having 4 + placements compared to 19 per cent in Finland. In the English case, there were young adults (16 \%) who had over nine placements, whereas, they did not exist in the Finnish case. 
The qualitative analysis can be divided into three different phases: initial researcher analysis by the lead academic researcher, collaborative analysis and then synthesis with peer researchers and practitioners. These phases were based on the interviews traditionally coded by the themes concerning well-being of young adults with help of Atlas-ti (the open questions) and with help of SPSS-program (the closed questions) to find patterns in the qualitative and quantitative data to help the comparison in the first phase by the lead researchers and then co-analysed and made a synthesis with the peer researchers and their practitioners. Here we use the analysed data connected to social relationships. In the excerpts nicknames are used for the interviewees to show their gender and the case.

\section{Findings}

The interviews of the young adults both in the Finnish case and the English case firstly tell how significant it is for them to be important for someone and to have someone who cares about them. They want to be seen as good and ordinary human beings and become accepted. Their answers strengthen the meaning of continuous social relationships for wellbeing. This continuity could be seen as an inherent element of reciprocal action in their past, present and future. That might be one reason why, although the questions concentrated on their present and their future, the interviewees brought to discussion also their past experiences.

The interviewees would like to have stability and feel meaningful, as themselves for some people, not only people who are moved from one place to another as part of a work task. These kinds of hopes about caring and emotional attachment seem to be similar both for the young adults in the Finnish and the English case study. They might represent universal needs and be the most important elements for the existence of human beings.

There is not a straight division of emotional participation and it cannot be divided mechanically into different categories. For instance, the interviewees have different experiences of participation in working life or studies. If we combine both cases there are 19 (27\%) young adults who did not have any work or study place, 21 (30\%) who are working and $30(43 \%)$ studying $(\mathrm{N}=70)$. However, this kind of division does not neatly divide their stories into different categories of emotional participation. It is of interest, however, that 
the bitter experiences and experiences of 'non-belonging' seemed to be more concentrated on the young adults who do not have any work or study place. These young adults might also be more worried about survival in their everyday life, not feeling that there is anyone who is supporting them.

There seem to be individual differences how these young adults have been supported. So, in this study it looks as if the practitioners who represent the system in both cases are individually flexible with young adults which helps to make the child and youth care services elastic. This also means that some young adults are supported more than others thus creating inconsistency in services.

The data shows that there are a variety of different positive and negative social networks and personal relationships. The connections individual young adults have seem to be more personal and individual, not only divided along the system of services or their private life. The data can be roughly divided into two parts on either end of the spectrum of emotional participation which reflect whether or otherwise their relationships are reciprocal and sustainable. These polarities illustrate that young adults either have many people supporting them or there is no personal or emotional connection. Young adults might have experiences with different people at both ends of the spectrum. This division clarifies the nature of relationships, support and advice that young adults describe receiving. This impacts whether they feel supported or alone when they start living independently.

\section{Sustainable social relationships: 'They have been there'}

'What has helped me the most. I think it's stability, knowing I've still got someone there, like by my side.' (Mike, English87)

Young adults with sustainable social relationships stress the meaning of others who they can trust. Typical for these relationships is that they are of a longitudinal nature and contain experiences of mutual sharing. These young adults are involved in others lives and are important to these people. These accumulated good experiences create emotions such that they feel they belong somewhere which empowers and gives self-confidence that they can 
take into other situations. This kind of interdependence is a crucial element of reciprocity and gives meaning to life.

Young adults with sustainable social relationships say that they have received help and support from both a family, extended family and friends and from social services or other organisations. Usually they have several persons who support them. They mention, for instance, friends, siblings, teachers, social workers or other officers from social services or other organisations, foster carers, residential staff, grandparents, members of the extended family, family or partner. Young adults in this category often mention a helpful person in social services by their first name. This indicates that they know each other as persons, not only as officers. Sometimes young adults struggle with the official titles of the workers, such as Independent Review officer or Personal Advisor in England.

The most help young adults in the English case seemed to get was from their friends, staff in the home, personal advisor and from staff from in other organisations. Surprisingly, they told that they got a little less support from their families, foster families or siblings when they started independent living. Whereas, in the Finnish case friends, siblings, parents and extended family had given more support than the officers after they had left care as experienced by the interviewees. When the Finnish young adults had been in care the officers had been more active and they had been in a range of forms of residential care. These differences might reflect in our data, the caps in the system but also how the relationships are built up, for instance, with extended family during the care. When foster caring is used more in the English case, it might also indicate that there is less emotional space for relatives than is the situation in the Finnish case whereas more residential care is used.

In personal relationships we might think that the people who are closest to us are people whom we tell about our difficulties or sorrows. When asked whom do you speak to if you feel sad most of the young adults spoke most regularly about their very special friend or some friends or their family such as their mother or dad or grandparents:

'My best friend that I've been friends with for eleven years. ...Just because she knows me inside and out, and we've been friends for so long.' (Sara, English20) 'Yeah, possibly my best friend. Her I tell my things first.' (Sauli (male), Finnish183) 
It seems important to young adults to have people who they have known for a long period which guarantees the continuity of their social relationships. It was also mentioned that these persons might bring to them some positive insights, not only focusing on difficult situations. When someone has known them for a longer period, it usually means that they do not need to tell who they are and not pretend to be someone else. They have a feeling that they are accepted as they are. They know that they are people who they can lean on. The social bonds are seen as very important, an emotional and spiritual home where they can feel comfortable and settled in each other's presence.

These findings resonate with Löfblom $(2016,5)$. She noticed that young adults' collective experiences stress the meaning of security, commitment, togetherness and they are proud about their hobbies, good friends, family and about people who they feel similar to. If the experiences are good they are grateful and they know whom to call and ask for help every time they feel they need it. These people are then connected to the most important decisions and choices they make in their life. These people support their emotional participation:

'They stuck by me and made me, I don't know, they made me feel normal, to be honest. Encouraged me, they encouraged me, to just get on with it now.' (Ann, English19)

Some young adults have strong collective experiences of similarity and shared mutual experiences with peers that have reinforced them in many ways. These peers were referred to in ways that suggest they were like role models 'They just did it' in terms of how they have organised their independent living. These role models give them hope that they themselves also have possibilities for a good independent living. Their peers might feel like their siblings or friends in different residential settings.

'There [in the children's home] are many other children, who have been like siblings, and when you have learned to share and tolerate... and it has been like a big family and the toleration and sharing with others have been important.' (Sanna (female), Finnish14)

'Yeah, I have always had older mates, who are working and give me some kind of model...' (Kaarle (male), Finnish105) 
They can share their experiences and feel that they are not the only ones who have difficulties and they can get help. Their successes in taking care of their everyday tasks strengthen their own capabilities and possibilities to make choices in the future.

Young adults with sustainable social relationships might be emotionally attached to the persons who have been close to them in care and they are satisfied with these relationships. Sometimes also foster carers, residential staff members or other workers remain in the life of young adults after they have left care. They may see that being in care has been a good solution for them, although there are usually also mixed feelings. If that is not the case, they might be emotionally attached to some other persons who are outside the system. Sometimes people in the family or extended family, like cousins, can support the feeling of belonging. So, there are some young people who felt that having other people who supported them is enough:

'I wouldn't really say there is, obviously not living on my own I wouldn't really say there is that many important things. I think the most important thing is, as I said before, you can have people around you. During my time in care, when I didn't have my family around, it was my carers and my friends, as well as teachers. So, being left at home on weekends, when everybody's gone out, I'm not really bothered, I can ring up my mates and we can go out. It's not an issue for me, at all.' (Sam, English71)

When young adults describe their bad experiences of being in care, they usually mention different kind of problems in relation to other people outside the care setting. Although they may be satisfied with their life situation and live happily in care they might be labelled by the neighbourhood, in the area where they live, for instance at school. In these settings the young adults often have difficulties in explaining why they are living apart from their family.

\section{Fragile and fragmented relationships: 'They just guided me'}

Unfortunately, some young adults' experiences described the help they received as advice given but with an emotional distance: 'They just guided me'. We call these social relationships fragile and fragmented. According to the interviewees there seemed to be an emotional distance to any adult figure, a feeling that you cannot trust, be yourself or be important and valued which in turn creates a feeling of loneliness and isolation. The reason 
for that might be that they have many social disappointments and bitter experiences. These young adults have difficulties in trusting anyone, only themselves: 'I don't talk anyone about how I feel. I just bottle it up sometimes.' (Lara, English67)

Advice rather than being part of a dialogue felt top-down. Social services have a long memory of young adults' past unfortunate acts and they can be interpreted through these lenses. This creates anger in their minds. It might be that they do not often meet other people who are proud of them because these interviewees had difficulties in praising themselves or seeing any successes in their life when asked. If they feel that they are not good enough, they have to hide their real feelings and pretend to be someone else. On these occasions, they described feeling themselves as aliens and left alone to the world. They felt that they had not become important to any adult figure.

Some young adults also learnt to hide their negative feelings and kept themselves to themselves. They learnt to act according to the wishes of others. As one young peer researcher stated, one-day they seem to be all right and in a good mood and the next day they feel suicidal. Some of them have learned to be kind outside and hide their anger which can turn in on themselves.

Independent living can create an even bigger distance to the people who young adults had felt close to earlier in their lives. Interviewees described being disappointed that the carers they were previously close to were already concentrating on other youngsters and thus their existence may not seem so meaningful anymore. Some young adults relayed stories of making different decisions on their own. For example, some interviewees told how they managed to organise their everyday life on their own almost without any support or help from adult figures:

'...They were never there... They don't answer. Or they're never in. Like, most of them were unhelpful because it was literally a fact of ticking boxes on paperwork. ... They didn't talk to me, and they just, you know when you just feel like people are just doing it so that they can say that they've done it on paperwork? I know how stupid it sounds, but just someone on the end of the phone to ask questions to. (Ann, English19)

'... because being a care leaver, so I couldn't ask for anything else.' (Lottie, English80) 'What can I say? (laughs) Cos I done it all by myself.' (Oliver, English69) 
Some interviewees had needed more support for their personal and emotional

development, especially with anxiety, rebuilding the relationships with family and extended family but also with budgeting. Just receiving advice does not seem to be enough. They would like to have someone to care and set limits for them:

Young adult: 'Yeah, much more limits ... I had needed... Don't know... the tighter boundaries.'

Peer interviewer: 'Do you mean that you yourself had to set these boundaries or did you want one adult to support you to do so?'

Young adult: 'At least in the beginning the adult.' (Katri (female), Finnish78)

This illustrates that there are some young adults who are leaving care alone and isolated not only from their family but also from the care system. It can feel like a new rejection when starting independent living or as if the system kicks them out like a mistreating parent.

Some of the young adults interviewed expressed a longing for their own biological family and had hoped to find their own roots. If the young adult had lost contact with their family, but were willing to renew the contact, they might start to build bridges with their family:

'Learning how to get put into a family again, like, building bridges with family. Cos now I'm just stubborn, I just shut off and don't care.' (Nick, English86)

It seems that if they do not have relations to their family or extended family, they find it very important to advise others to find their family roots, for example: Stay in contact with your close relatives (Olivia, English01).

However, there might be disappointments for young adults if it did not work in the way they had hoped for with their biological parents, siblings or extended family. The time in care may have alienated young adults from their family and extended family. The young adults sometimes stated that they did not care but the way in which they do it suggests their disappointment about the situation.

Although many young adults had hoped to get rid of 'care', they were surprised about the feelings of loneliness or emptiness afterwards. They felt that they lost their hold on the real world. They might not have a place to study or work, and they did not know how to solve these questions, although they are important to them. They are worried about their finances and that they cannot pay their rent or other bills and are afraid that they may lose their apartment. (See Törrönen and Vauhkonen 2012a, 55). 


\section{Discussion}

The strong message from young adults in this research both from the English and the Finnish interviewees is the importance of stability. It includes the idea that there is some continuity in the social relationships and places where they can feel at home.

The article shows how experiences of emotional participation among young adults leaving care vary from each other. So, there is not only one kind of stereotype of the young adults' experiences of emotional participation. We analysed young adults' own descriptions of their relationships, social support and advice they received when starting independent living after being in care after living in foster families or in residential care.

The obstacles for creating good relationships which support the practice of reciprocity and feeling of emotional participation are reflected in both the Finnish and English cases: the long emotional as well as sometimes physical distances to friends and extended family members where parents and the extended family have become like acquaintances; losing their relationships with their foster parents; loneliness; not being aware of aftercare possibilities; independent living having been prepared for, but where there is also a remarkably short preparation time; experiences of being treated badly and insecure situations regarding finances and the future.

In the data, it seems if life enables the potential to make meaningful relationships, for instance if they are studying or working or both, it helps to create belonging. Also, when young adults experience social support both from residential staff or foster parents and possibly from extended family members or friends they know whom to ask for help if they need it. Very important seem also be their own attitude and their good future prospects and experiences how they are satisfied with their own life situations and whenever they experience that being in care has stigmatised them.

Despite the common themes of wanting to be important for someone in both Finnish and English case studies there are differences in how services are organised or even obstacles for emotional participation created by the system in these two cases and what kind of services are delivered. 
The interviewees have their last experience of care usually either from foster care or residential care and there was a clear difference between the cases. In the English case, in the study region, the main provision of services is in foster care, although the interviewees also have experiences of residential care, whereas in the Finnish case both residential care and foster care are used but the main stress is on the different forms of residential care. Usually in Finland smaller children are placed in foster families and the adolescents to different forms of residential care, which are usually small and home-like entities. Behind these differences lies a different contextual history of child welfare but it also reflects a certain limit to the understanding of 'the best interest of the child' and unfortunately also the costs of care. Foster caring is cheaper but it contains the idea of family surroundings offered to the child. Whereas, in residential care the meaning of peers is important but also the staff changing in shifts. In both places there are both good and bad experiences. So, it looks like the form of care is not the most important element for emotional participation but rather the individual connectedness to someone in whose eyes you look good enough. The interviewees were most often happy about getting out of care but afterwards maybe longed for the time when someone was taking care of the practicalities, and also for company. In terms of negative experiences, they tell about the feelings that someone was keeping an eye on them and even some of them experienced mistreatment.

In the Finnish case, some use language which describes leaving care like being freed from a total institution like a prison. It sounds like they have completed their prison sentence and have been freed. These experiences might tell about institutional care and the discipline and the rules of these places. However, the rules and emotional participation seem to vary according to the residential homes and their workers and their personal relationships to the young adults.

In the English case the young adults have more experiences of foster families because the region does not have residential homes of its own. The residential institutions are owned by private entrepreneurships. Sometimes young adults were also sent outside the county borders to other residential institutes. Some of the interviewees had experiences of residential care too. Young adults' experiences of foster families varies a lot. Some families treated them as their own children, whereas, in some families they were not even allowed to use the family dishes and had separate dishes. They might not be taken on summer 
holidays with the other family or did not have pictures of themselves visible in the homes they stayed in. Whereas, some young adult get help and support even after they have left care and they are confident to have a person to lean on.

Another difference is that there is a tension between interdependence and independency which this comparative analysis brings into focus. They reveal the different ideologies behind the child and youth services which impacts on practice. The English practice is more child protection oriented than the Finnish practice is more like individualised liberty-practice.

In the English case, there is a strong stress on 'risk assessment' which affects the working traditions both for workers but also for young people in care. In foster care or residential care risk assessment demands a lot both from workers, foster parents or young adults to protect children from the potential risks. Risk assessment means that workers have to assess and try to prevent the potential risks and with administrative forms to show and secure what is done, for instance in cases of accidents. For example, young adults might not be allowed to go after school to meet friends because the foster parents or staff need to know where they are and make a risk assessment of their activities, for instance if they would like to go cycling. So, there might be some difficulties to build up relationships - for instance to their classmates - if they do not have spontaneous opportunities to socialise with them. So, risk assessment and varying understanding of it may hinder the building up gradually of independency and strengthen the interdependency with other people than the practitioners.

Whereas, in the Finnish case young adults seem to be more independent in both residential and foster care. It gives them usually possibilities to move more independently than in the English case in their free time but it might also give more possibilities to risk their wellbeing. Although there are - especially in the beginning of care - some restrictions and control over them, there seems to be more freedom for the young adults in the Finnish case to do things on their own and meet their friends. It indicates that there is a certain trust of the young adults leaving care and also highlights the traditional value of independency or liberty. However, it might also create feelings for the young adults that nobody really cares about them and their life and the responsibility of individual choices they make lies on them. 
One similarity in both cases is the rough division of sustainable or fragile and fragmented social relationships. It is important in social work research to describe also the positive outcomes of the work done but not forget those who have it the most difficult. The difficulties show that there are not supporting adults for every young adult when he or she starts independent living. It tells also that social relationships cannot always be supported with any measures; they can break down and cannot be build up, however, they can be replaced with other social relationships. As love can be shared, so also parenthood and friendship. Also, the life situations for young adults cannot be interpreted as static because they are in constant change.

Although there seems to be either positive or negative accumulation in the life situations of young adults, it cannot be understood solely individualistically. The problems are created in co-operation with others, in the communities where the young adults are acting, and so the difficulties reflect the social relationships and their quality in these communities. If they do not feel that there is anyone supporting them, they might be separated from the community. The community, also the child and youth services, might reject them. So, the difficulties are not only individual but more collective; the young adult has not learned how to act reciprocally because they might not have experienced how people can be kind to each other and help each other. Good acts usually create interdependence among people and feelings of togetherness.

\section{Conclusion}

How to support stability, develop reciprocal relationships and thus build up better emotional participation? The nature of care should be temporal but for many young adults in this research it seems more longitudinal. Should the practice of child and youth services figure out more life-long visions rather than focus on a certain period of the young adults' childhood? If so it would mean stressing not just individualistic practice but placing more emphasis on community practice which takes into consideration, for instance, biological parents, extended family members or other collectives. If young adults could have relationships with the same people they have known during care, it would make the start of independent living easier. Also, if they could start their independent living according to 
their own wishes until they are at least 25 years old, could it help them for instance to finish their education and have a flexible start to independent living? For the start of leaving care the young adults suggested there should be some kind "buddy system or safety network", like another care leaver who's gone through the whole move.

The changes of placements also brings to mind a question of what kind of expectations there are on young adults and on what kind of knowledge this is based on? What does it imply about the work orientation of workers and foster carers? For instance, Canadian researcher Rebecca Ward $(2016,105)$ has very critically pointed out that in out-of-home care there is a need for therapeutic and empowering connection to children which demands reciprocity. She views a pathological orientation as dangerous because it is based on punishments to dominate the youth behaviour and sees that young people are usually then resistant and difficult to support. In this study, we cannot answer that question but it is an idea for further research in relation to stability and emotional participation.

Continually experiencing exclusion may cause an individual to disapprove of others and seek the company of those who do not exclude him or her and who offer approval. If people feel that they are outsiders, this can create aggression and anger at social injustice. Thus, it is increasingly important that we understand how being a reciprocally active participant in society increases emotional participation. Although, new liberal ideas stress individual choice and responsibility, we need solidarity and shared responsibilities to feel well (see Lindenberg et al. 2010).

\section{References}

Becker, L.C. 1986. “Reciprocity.” London: Routledge \& Kegan Paul.

Coleman, J. S., 1990. Foundations of Social Theory. Massachusetts: The Belknap Press of Harvard University Press.

Cotterell, P. 2008. "Exploring the value of service user involvement in data analysis: 'Our interpretation is about what lies below the surface". Educational Action Research16 (1): 5-17.

Daly, W. 2009. "Adding their flavor to the mix": Involving children and young people in care in research design. Australian Social Work, 62 (4), 460-475.

Franklin, A. and Sloper, P. 2006. Participation of Disabled Children and Young People in Decision Making Within Social Services Departments: A Survey of Current and Recent Activities in England. British Journal of Social Work 36, 723-741. 
Holland, S., Renold, E., Ross, N., and Hillman, A. 2008. Rights, 'right on' or the right thing to do? A critical exploration of young people's engagement in participative social work research. Working paper-Qualiti/WPS/006.

"Involve." 2016. Involving children and young people in research: top tips and essential key issues for researchers. NHS National Institute for Health Research. Involve, Eastleigh, pages 11.

Kellett, M. 2003. "Children as active researchers: a new research paradigm for the $21^{\text {st }}$ century?" ESRC National Centre for Research Methods. NCRM Methods Review Papers. (no page numbers), pages 36 .

Korkiamäki, R., and Ellonen, N. 2010. Ikätoverisuhteet sosiaalisina resursseina yläkouluiässä. [Peer relationships as social relationships in the secondary school.] Nuorisotutkimus 28 (3): 18-35.

Lindenberg, S.M., Fetchenhauer, D., Flache, A., and Buunk, A.P. 2010. "Solidarity and prosocial behaviour: A framing approach." In Solidarity and prosocial behavior: An integration of sociological and psychological perspectives (critical issues in social justice), edited by D. Fetchenhauer, A. Flache, A.P. Buunk, and S.M. Lindenberg. New York: Springer, 23-44.

Löfblom, K. 2016. "Nuorten kokemat yhteisolliset elämykset." [The collective experiences of young people.] Nuorisotutkimus 34 (4): 5-21.

Mayer, J., and Timms, N. 1970. The Client Speaks. New York: Atherton Press.

Morrow, V. 1999. "Conceptualising social capital in relation to the well-being of children and young people: A critical review." The Sociological Review 47: 744-765.

Newcomb, M. 1990. "Social support by many other names: Towards a unified conceptualization." Journal of Social and Personal Relationships 7: 479-494.

Nyman, J., Arffman, M., and Keskimäki, I. 2017. Terveyspalvelujen käyttö Helsingissä vuonna 2014. [The use of health services in 2014 in Helsinki.] Sosiaalilääketieteellinen aikakauslehti 54 (4): 310-326. Accessed 8 December 2017. https://journal.fi/sla/article/view/67761.

O'Brien, N. 2016. "To 'Snitch' or Not to 'Snitch'? Using PAR to Explore Bullying in a Private Day and Boarding School." A thesis in partial fulfilment of the requirements of Anglia Ruskin University for the degree of Doctor of Philosophy. Submitted: $9^{\text {th }}$ December 2015. Accessed 13 April 2017. http://arro.anglia.ac.uk/700970/

Ostrom, E., and Walker, J., eds. 2003. Trust and reciprocity: Interdisciplinary lessons from experimental research. New York: Russell Sage Foundation.

Participation Models, Citizens, Youth, Online. A chase through the maze. November 2012. $2^{\text {nd }}$ edition. Accessed $1^{\text {st }}$ September 2016. http://www. nonformality.org/participationmodels 
Paulsen, Veronika \& Berg, Berit (2016) Social support and interdependency in transition to adulthood from child welfare services. Children and Youth Services Review 68, 125-131.

Putnam, R. D. 2000. Bowling alone. The Collapse and Revival of American Community. New York: Simon \& Schuster.

Saarikallio-Torp, M., Heino, T., Hiilamo, H., and Hytti, H. 2010. Lapset huostassa, vanhemmat ahdingossa. [Children in care, parents in troubles.] In Perhepiirissä, edited by Hämäläinen, Ulla, and Kangas, Olli. Helsinki: Kela, 236-265.

Saleebey, D. 1997. The Strengths Perspective in Social Work Practice. New York: Longman cop.

Stein, M. and Verweijen-Slamnescu, R., eds. 2012. When Care Ends: Lessons from Peer Research. Insights from young people on leaving care in Albania, The Czech Rebublic, Finland, and Poland. Wien: SOS Children's Villages International. Accessed 13 April 2017. http://www.sos-childrensvillages.org/getmedia/80a754d9-8832-4a16-9e7e11ece55b23e0/PeerResearch-European-Report-WEB.pdf

Törrönen, M. 2017. "Creating well-being through reciprocal relationships." In Reciprocal Relationships and Well-being: Implications for Social Work and Social Policy, edited by Maritta Törrönen, Carol Munn-Giddings, and Laura Tarkiainen. London: Routledge \& Taylor \& Francis.

Törrönen, M., Munn-Giddings, C., and Tarkiainen, L., eds. 2017. Reciprocal Relationships and Well-being: Implications for Social Work and Social Policy. London: Routledge \& Taylor \& Francis.

Törrönen, M. 2015. "Toward a Theoretical Framework for Social Work-Reciprocity: The Symbolic Justification for Existence." Journal of Social Work Values and Ethics 12 (2): 77-88. www.jswve.org.

Törrönen, M. and Vauhkonen, T. 2012a. "Itsenäistyminen elämänvaiheena, Osallistava vertaistutkimus sijaishuollosta itsenäistyvien nuorten hyvinvoinnista" [Leaving care as a phase of life - Participatory peer research of well-being of young people leaving care]. Helsinki: SOS-Lapsikylä ry.

Törrönen, M. and Vauhkonen, T. 2012b. "Everyone is valuable - participatory peer research into young people leaving alternative care." SOS Children's Village Association. Accessed 13 April 2017.

https://www.researchgate.net/publication/262004169 Everyone is valuable Participatory peer research into young people leaving alternative care

Ward, A. (2010). What is 'self'? CYC-Online, 139. Available at http://www.cyc-net.org/cyconline/cyconline-sep2010-ward.html. Assessed 24th November, 2017.

Ward, R. 2016. Can Professionalization legitimize Relational Child and Youth Care (CYC)? Relational Child \& Youth Care Practice, The CYC-Net Press, Volume 29, Issue 4, 103-112. 
Winter, R. and Munn-Giddings, C. 2001. A handbook for Action research in health and social care. London: Routledge.

Table 1: Characteristics of young persons leaving care

\begin{tabular}{|l|l|l|}
\hline & $\begin{array}{l}\text { FINNISH CASE } \\
\mathbf{N}(\%)\end{array}$ & $\begin{array}{l}\text { ENGLISH CASE } \\
\text { N (\%) }\end{array}$ \\
& & \\
\hline GENDER & & \\
\hline Female & $27(54)$ & $8(33)$ \\
\hline Male & $23(46)$ & $16(67)$ \\
\hline Total & $50(100)$ & $24(100)$ \\
\hline NUMBER OF PLACEMENTS & & \\
\hline 1 & $10(22)$ & $6(25)$ \\
\hline $2-3$ & $27(59)$ & $9(39)$ \\
\hline $4+$ & $9(19)$ & $9(36)$ \\
\hline Total & $46(100)$ & $24(100)$ \\
\hline LAST FORM OF PLACEMENT & & \\
\hline Residential Care & $22(44)$ & \\
\hline Foster Care & $16(32)$ & $11(46)$ \\
\hline Semi-independent & & $9(37)$ \\
\hline Other & $12(24)$ & $4(17)$ \\
\hline Total & $50(100)$ & $24(100)$ \\
\hline STUDYING AND EMPLOYMENT & & \\
\hline Studying & $21(46)$ & $5(21)$ \\
\hline Employed & $16(35)$ & $9(37)$ \\
\hline Neither & $9(19)$ & $10(42)$ \\
\hline Total & $46(100)$ & $24(100)$ \\
\hline & & \\
\hline
\end{tabular}

